\title{
The design of a volleyball training drill: definition of parameters and assessment of drills' contents
}

\author{
Desenho de exercícios de treinamento de voleibol: definição de parâmetros e avaliação do \\ conteúdo dos exercícios \\ Diseño de ejercicios de entrenamiento de voleibol: definición de parámetros y evaluación \\ del contenido de los ejercicios
}

Thiago Machado ${ }^{a, b, *}$ (D) , Wellington Rangel ${ }^{b}$ (D) , Leonardo Lamas $^{b}$

Keywords

Teaching;

Model;

Planning;

Team sports.

\begin{abstract}
The aim of this work was to define a model of volleyball drills' structure. A set of parameters has been designed and tested for: i) pertinence and accuracy; ii) criteria reliability; iii) practical application. Expert judges evaluated model's pertinence, accuracy and criteria reliability. A sample of 50 drills was assessed for drills' analysis. The model demonstrated pertinence and accuracy, with complete agreement among experts. Criteria were reliable (Kappa test results $>0.8$ ). Analysis indicated significant differences in the frequency of model's parameters (graph topology), for instance among attributes (basic complex - 30\%) with manifold drills $(46,7 \%)$ in the technical domain (100\%). The model contributes with theoretical support for a coach's key task of designing practice contents.
\end{abstract}

Palavras-chave

Ensino;

Modelo;

Planejamento, Esportes coletivos.

\section{RESUMO}

O objetivo deste trabalho foi definir um modelo de estruturação de exercícios de treinamento no voleibol. Um conjunto de parâmetros foi determinado e testado por especialistas quanto a: i) pertinência e precisão; ii) confiabilidade; iii) aplicação prática. Uma amostra de 50 exercícios foi avaliada com base no modelo. 0 modelo demonstrou pertinência e precisão, com total concordância entre os especialistas. Os critérios foram confiáveis (resultados do teste Kappa $>0,8)$. A análise indicou diferenças significantes na frequência dos parâmetros do modelo (topologia do grafo), por exemplo entre atributos (complexo básico - 30\%) com tarefas múltiplas $(46,7 \%)$ no domínio técnico (100\%). O modelo contribui com suporte teórico ao treinador em sua função-chave de planejar os conteúdos de treinamento.

\section{RESUMEN}

El objetivo de este trabajo fue definir un modelo de la estructura de tareas de entrenamiento em voleibol. Un conjunto de parámetros fue determinado y evaluado por expertos cuanto a: i) pertinencia y precisión; ii) fiabilidad; iii) aplicación práctica. Se evaluó una muestra de 50 ejercicios según el modelo. El modelo demostró pertinencia y precisión, con total acuerdo entre los expertos. Los criterios fueron confiables (resultados del teste Kappa $>0.8$ ). El análisis indicó diferencias significativas en la frecuencia de los parámetros del modelo (topología del grafo), por ejemplo entre atributos (complejo básico - 30\%) con múltiples tareas (46.7\%) en el dominio técnico (100\%). El modelo aporta suporte teórico al entrenador en su papel clave de diseñar el contenido de entrenamiento.

annstituto Federal de Educação Ciência e Tecnologia de Brasília, Brasilia, DF, Brasil.

bUniversidade de Brasília, Faculdade de Educação Física, Brasilia, DF, Brasil.

*Corresponding author:

Thiago Machado.

E-mail: thiago.costa@ifb.edu.br 


\section{INTRODUCTION}

In volleyball, team performance is conditioned by technical, tactical, and strategic contents, and players learn from these contents through the training practices. To qualify practice is key for performance, which depends on the correct choice of drills in view of the team's improvement needs (Palao and López-Martínez, 2012; Sarmento et al., 2015).

In training practices, drills address game problems whose repetitive exposure provides players greater competence to solve them (Shondell and Reynaud, 2002; Spooner, 2012). In net sports, training practices have been investigated through two main approaches. In one of them, it has been investigated the effect of training drills on physiological parameters (Nieman et al., 2000; Ferrauti et al., 2001; Reid et al., 2007; Ghosh, 2008).

Alternatively, other studies focused on the development of training contents. Some of the investigations consider parameters such as duration, number of players, playing space, presence and levels of opposition, technique of execution, presence of decision making elements, game phase and combinations of players' interactions (Morcillo et al., 2001; Sá, 2001; Toro and De Baranda Andujar, 2003; Leite et al., 2009; Spooner, 2012; Ibáñez et al., 2016). Still, some works investigated elements of organization and evolution of tasks, suggesting ways to improve the efficiency of time and space manipulation (Shondell and Reynaud, 2002; Vélez et al., 2004; Andrés and Peña, 2006; Andrés et al., 2007). However, these parameters have been addressed in isolation. The existing literature does not present a model that defines the way in which the various parameters that compose the design of a training drill should be articulated and how they relate to the training goals.

The absence of systematization of the parameters that define the structure of the training drills (Milistetd et al., 2010; Matias and Greco, 2011) reinforces the empirical approach of sportive coaches in this regard (Lamas et al., 2013; Partington and Cushion, 2013), whose drills' design are frequently based on own experience and interaction with peers (Côté, 2006; Cushion et al., 2010; Resende et al., 2014). Obviously, previous experience and knowledge exchanges have an important role in qualifying professional intervention of coaches. However, it is enhanced by the scientific approach with its uncontroversial contribution to sports science (Nevill et al., 2008).

Hence, the aim of this study was to create a model encompassing the attributes and parameters that define the structure of any volleyball training drill.

\section{MATERIALS AND METHODS}

The definition of the set and the sequencing of the elements used in the design of volleyball drills was carried out through the following steps.
First, we defined a set of attributes, which comprises the volleyball game complexes (Hileno and Buscà, 2012; Moraes, 2009) and classes of training domains (e.g. team tactics, technical skills, etc). Additionally, we specified the classes of parameters, and respective levels, that define a training drill. Second, we tested the attributes and parameters in terms of their pertinence and accuracy for decomposing a volleyball training drill and classify its structure. Third, we evaluated the reliability of attributes' and parameters' criteria. Fourth, we used the model to analyze the design tendencies of volleyball training drills from a state-of-art dataset.

\section{MODELING VOLLEYBALL TRAINING DRILLS' STRUCTURE}

The aim of this step was to define a set of parameters that would be adequate to describe the structure of any volleyball training drill. The preliminary model was conceived based on the researches' expertise, consultation of the literature and data analysis of training drills. The modeling process encompassed several iterations between conception of the model's structure and analysis of training drills for conference of structure's adequacy. The review at this stage was done by consensus between the researchers, including argumentation to defend each point of view when necessary (Santana et al., 2019).

All levels of the model (e.g. game complexes, domains, parameters) were assessed for the evaluation of its pertinence and accuracy (Palao et al., 2015; Santana et al., 2019). Pertinence indicates the adequacy of the resolution level applied. If it was excessively general or specific, classes could be, respectively, separated or combined (Santana et al., 2019). Definition accuracy indicates whether the class was properly defined, with clear criteria (Santana et al., 2019). Evaluation focused on making attributes and parameters meaningful and clearly communicated within the volleyball community. Judges complemented their expert analysis by applying the model to decompose volleyball drills. A positive outcome for pertinence occurred whenever we verified a matching between the structure of the drill and the level of attributes and parameters of the model. Complementary, we evaluated the accuracy of the model using a binary criterion. The drill should test true for the matching with one and only one alternative of attribute or parameter. For example, the drill should test true for one domain (e.g. strategic, collective tactic, etc.) and only one. Otherwise, the class of attribute or parameter was considered inaccurate. Thus, attributes and parameters of the model had to present a matching with the training drill inspected to be considered pertinent. And the matching had to be exclusive to be accurate. Nonpertinent or inaccurate attributes and parameters were submitted to researchers' appreciation and remodeling.

We performed an intra-rater reliability test to verify the consistency of an observer in applying the criteria 
of attributes and parameters. A set of ten training drills encompassing contents from all attributes of the model were randomly selected and submitted to evaluation by a judge. The judge was an experimented volleyball coach with five years of experience. There was a washout period of one-month between analyses. Analysis was performed trough the notation of video footages of the drills. For each drill, the judge was oriented to decompose the drill's structure searching for a matching with the parameters of the model.

Finally, we applied the consolidated set of attributes and parameters to analyze contents' recurrences in real training drills. For this purpose, we mapped the inherent structure of training drills into the attributes and parameters of the model.

\section{SAMPLE}

The sample assessed for pertinence and accuracy purposes consisted in a sub-set of the drills' library of the American Association of Volleyball Coaches, publicly available as digital videos. For each content domain (strategic, collective tactics, group tactics, individual tactics, technical), we randomly selected ten drills from the library ( 50 drills, in total, were analyzed considering all domains). The sample was used to the analysis of drills' contents design as well.

\section{DATA ANALYSIS}

The evaluation of the pertinence and accuracy of the attributes and parameters consisted in computing any semantic inconsistency in the analysis of training drills in regards to the categorical classes of attributes and parameters. For pertinence there was expected a matching between attribute or parameters and respective structural element of the drill. For accuracy, there was expected a univocal matching between the attribute or parameter and the respective structural element.

Second, we assessed the reliability of attributes' and parameters' criteria. For this purpose, we performed an intra-rater reliability test to verify the consistency in applying the parameters criteria. The gathered data was evaluated through the Kappa test (Landis and Koch, 1977). Kappa coefficient related to the following agreement level scale: $<0$ less than the chance agreement, 0.01-0.20 slight agreement, 0.21-0.40 fair agreement, 0.41-0.60 moderate agreement, $0.61-0.80$ substantial agreement, and 0.81-0.99 almost perfect agreement (Landis and Koch, 1977).

Third, we performed a graph network analysis to characterize general design tendencies of the training drills. We assessed the centrality of the different parameters in their sequential connections to generate the drills. In the graph representation, nodes and edges have, respectively, diameter and thickness proportional to the frequency of occurrence. Analysis was performed with igraph package from $R$ statistical software.
Forth, we applied the Fischer's exact test to analyze differences in the frequencies of the attributes in the 50 training drills of the sample, grouped according to the game complex. We summarized the attributes identified in the drills with tree diagrams.

\section{RESULTS}

\section{PERTINENCE AND ACCURACY}

The final set of attributes and parameters of a model of volleyball training drills structure presented a satisfactory performance both for pertinence of the classes and respective accuracy definition. Cases of semantic inconsistencies leaded to remodeling until consensus among judges. The final version of the model indicated attributes and parameters presented univocal relations when paired with the drill's structure, evidencing a successful decomposition. The consolidated set of attributes and parameters will be presented in the sequence.

\section{ATTRIBUTES OF THE MODEL}

In volleyball, sequences of actions define game complexes (Moraes, 2009). Thus, complexes support the organization of the game in subsets of actions, which is helpful for designing training drills. The game can be divided into six complexes (Moraes, 2009; Hileno and Buscà, 2012): $\mathrm{KO}$ represents the service; $\mathrm{KI}$ - actions that occur from the service reception until the offense is completed; KII - actions that occur after a team defends itself against an opponent's attack; KIII - actions after a team defends itself against an opponent's counterattack; KIV - actions required to start a new offense after the previous one has been neutralized; KV - actions initiated from the defense of a ball with a low risk of scoring. In a given complex, consecutive actions can be grouped into subsets called complex parts (Kp). In each complex, drills may relate to the strategic, tactical and technical domains of the game, whose definition is presented in Table 1.

In the formulation of a training drill, explicitly or not, sequencing starts with the complex involved and then the definition of the domain associated with the complex. These two steps correspond to the specification of the attributes of the training content. The attributes are combined with parameters to design the training drill properly. The parameters will be defined in the following.

\section{PARAMETERS OF THE MODEL}

The parameters modulate the training drill and are subdivided into structure and functional parameters.

\section{STRUCTURE PARAMETERS}

Structure parameters are defined through three hierarchically dependent levels. The first order parameters are: i) Opposition (OP) - specifies interaction with an opponent; ii) Ball interaction (BI): specifies how 
the contact with the ball occurs; iii) Instruction type (IT): coach's choice to proceed with the instruction (Table 2).

Second order parameters are defined consistently with the specifications of the first order parameters (Table 2). Similarly, the third order parameters are defined consistently with the second order parameters (Table 3 ).

The implementation of structure parameters is not sufficient to characterize a training drill, since they represent only properties of the drill. The drill's dynamics depends on spatial and temporal specifications. The drill's dynamics is determined by the implementation of functional parameters.

\section{FUNCTIONAL PARAMETERS}

The functional parameters add spatial and temporal elements over the parameters of structure. Three firstorder functional parameters should be considered: i) kinematic, ii) pressure; iii) logistic.
The kinematic parameter is divided in two classes: i) ball trajectory; ii) players' displacement complexity. Both are time-dependent and used to specify the beginning, course and end of the action (Table 4). The ball's trajectory class is defined by two factors: i) unpredictability of the trajectory; ii) time evolution. Player's displacement complexity is defined by the dynamics of each player's positioning (i.e. magnitude and speed of movement, and the amount of changes in direction) at the beginning, course and end of the action.

The pressure parameter (Table 5) combines spatial and temporal constraints of pressure: i) rhythm (i.e. level of temporal pressure); ii) amplitude of attention (i.e. number of stimuli to be processed); iii) type of start (i.e. type of ball handling skill to start the task).

The logistic parameter (Table 6) refers to the periodicity of the actions and their consequences for training practice organization, being divided in the classes:

Table 1. Definition of volleyball's game domains applied to the classification of training practices contents.

\begin{tabular}{|c|c|}
\hline $\begin{array}{l}\text { Content } \\
\text { domain }\end{array}$ & Description \\
\hline Strategic (ST) & $\begin{array}{l}\text { Content that allows players to perform, without interference from the opponent, the actions and } \\
\text { formations specified in the team strategy. Necessarily practiced without opposition. Examples: 'walk- } \\
\text { through' of court positioning, analysis of game excerpts from the opposing team, etc. }\end{array}$ \\
\hline $\begin{array}{l}\text { Collective } \\
\text { Tactics (CT) }\end{array}$ & $\begin{array}{l}\text { Composed of drills that reach the highest degree of similarity with the game in terms of the complexity } \\
\text { of game problems, while maintaining the functional configuration of the sport. It is performed with } \\
\text { opposition. Example: } 6 \times 6 \text { situational. }\end{array}$ \\
\hline$\underset{\text { (GT) }}{\text { Group Tactics }}$ & $\begin{array}{l}\text { Practice of the interaction between players that, based on synchronized individual actions, coordinate } \\
\text { themselves in order to continue a chain of situations coherent with the functional structure of the game } \\
\text { and the team strategy. It encompasses between two and five players, with opposition. Example: } 2 \times 2 \text { to } 5 \times 5 \\
\text { situational, numerical superiority or inferiority. }\end{array}$ \\
\hline $\begin{array}{l}\text { Individual } \\
\text { Tactics (IT) }\end{array}$ & $\begin{array}{l}\text { Practice of decision-making processes and respective physical implementations at the individual level in } \\
\text { face of game problems. In specialized game systems, they are closely related to the specific role of each } \\
\text { player. Example: attack in specific position against various types of block. }\end{array}$ \\
\hline Technical (TC) & $\begin{array}{l}\text { Practice of motor skills required in the game in order to be performed as efficiently as possible. Example: } \\
\text { exchange of } 1 \times 1 \text { overhead pass. }\end{array}$ \\
\hline
\end{tabular}

Table 2. Structure parameters (first order).

\begin{tabular}{ll}
\hline \multicolumn{1}{c}{ Parameter } & \multicolumn{1}{c}{ Description } \\
$\begin{array}{l}\text { Opposition } \\
\text { Without opposition (W/O) }\end{array}$ & $\begin{array}{l}\text { Absence of opponent } \\
\text { Formal (FM) }\end{array}$ \\
$\begin{array}{l}\text { Modified (MF) } \\
\text { N/D (NA) }\end{array}$ & $\begin{array}{l}\text { Number of opponents according to official rules } \\
\text { Interaction with the ball }\end{array}$ \\
Without ball (WB) & No contact with the ball \\
Catched (CD) & Retention after contact \\
Conventional (CV) & Contact according to the official rule \\
Control (CO) & Consecutive contacts to keep the ball in the air \\
Educative (ED) & Contact partially or fully compatible with official rules \\
N/D (NI) & Not applicable \\
Instruction & \\
Theorectical (TH) & Stimulation to declarative knowledge. Performance analysis in games and practices \\
(numerical, videos, etc)
\end{tabular}


Table 3. Structure parameters (second and third order)

\begin{tabular}{|c|c|c|c|}
\hline $1^{\text {st }}$ Order & $2^{\text {nd }}$ Order & Description & 3rd Order \\
\hline \multirow[t]{13}{*}{ Opposition } & Number of players & & \multirow{4}{*}{$1 \times 0,1 \times 1,1 \times 2,2 \times 0$, etc. } \\
\hline & Regular (RG) & According to the official rules & \\
\hline & Altered (AT) & Different from the official rules & \\
\hline & N/D (NP) & Not applicable & \\
\hline & Tactical roles & & \multirow{3}{*}{$\begin{array}{l}\text { Hitter; Setter, Outside Hitter, Right } \\
\text { Side Hitter, Middle Blocker; Libero }\end{array}$} \\
\hline & Specific role (SP) & $\begin{array}{l}\text { Player performs according to pre- } \\
\text { defined tactical role }\end{array}$ & \\
\hline & Non-specified role (NS) & Every player performs each action & \\
\hline & \multicolumn{3}{|l|}{ Game field } \\
\hline & Unchanged (UC) & According to the official rules & Net height \\
\hline & & & without net; lower; official; higher \\
\hline & Changed $(\mathrm{CH})$ & Different from the official rules & \multirow{3}{*}{$\begin{array}{l}\text { Court size } \\
\text { irrelevant; lower; official; higher }\end{array}$} \\
\hline & & & \\
\hline & No field (NF) & Without field & \\
\hline \multirow{10}{*}{$\begin{array}{l}\text { Interaction wit } \\
\text { the ball }\end{array}$} & & & \multirow{6}{*}{$\begin{array}{l}\text { Score } \\
\text { absent; unitary; differentiated by } \\
\text { objective }\end{array}$} \\
\hline & Outcome & & \\
\hline & Absent $(A B)$ & Continuous action & \\
\hline & After action (AA) & Achievement of a specific goal & \\
\hline & After rally (AR) & Score a point according to official rules & \\
\hline & N/D (NO) & Not applicable & \\
\hline & Game skills & & \multirow{4}{*}{$\begin{array}{l}\text { Posture; displacement; overhead } \\
\text { pass; forearm pass, serve; spike; tip; } \\
\text { block; roll, diving }\end{array}$} \\
\hline & Free (FR) & According to the player's choice & \\
\hline & Specific (SPS) & According to pre-defined skill & \\
\hline & N/D (NSK) & Not applicable & \\
\hline \multicolumn{4}{|l|}{ Instruction } \\
\hline & Implement & & \multirow{3}{*}{$\begin{array}{l}\text { Target; Beacon; Corrector; } \\
\text { Simulator; Facilitator; Distraction } \\
\text { element }\end{array}$} \\
\hline & No implement (WI) & Absence of accessories & \\
\hline & With implement (WOI) & Presence of accessories & \\
\hline & Instructional resources & & \multirow{3}{*}{ Filming; White board; Scout; Video } \\
\hline & No resources (NR) & Absence of accessories & \\
\hline & With resources (WR) & Presence of accessories & \\
\hline
\end{tabular}

i) density (relation between the time in effective activity and the time of pause); ii) concatenation (presence and manner of carrying out activities by all players in the same period of time); iii) cyclicity (existence of periodic and uninterrupted repetition of a set of actions).

To summarize the model, in Figure 1 we present a pictorial view of the complete process of volleyball training drill design, considering the sets of attributes and parameters.

\section{CRITERIA RELIABILITY}

Symmetry test of the Kappa values indicated no significant differences within observer on identifying classes of attributes and parameters of the model 
Table 4. Kinematic parameter classes: unpredictability of the ball trajectory and players' displacement.

\begin{tabular}{|c|c|}
\hline \multicolumn{2}{|r|}{ Unpredictability of the ball trajectory } \\
\hline \multicolumn{2}{|l|}{ Start } \\
\hline Low (LTS) & Ball trajectory is pre-defined and known \\
\hline Medium (MTS) & Ball trajectory is limited in alternatives, which are known from the beginning \\
\hline High (HTS) & Ball trajectory is unknown and has unlimited variability \\
\hline N/D (NTS) & Not applicable \\
\hline \multicolumn{2}{|l|}{ Course } \\
\hline Low (LTC) & Ball trajectory is pre-defined and known. \\
\hline Medium (MTC) & Ball trajectory is limited in alternatives, which are known from the beginning \\
\hline High (HTC) & Ball trajectory is unknown and has unlimited variability \\
\hline N/D (NTC) & Not applicable \\
\hline \multicolumn{2}{|l|}{ End } \\
\hline Low (LTE) & Ball should be attacked in specific regions \\
\hline Medium (MTE) & Ball should be attacked in specific regions with attacking skills previously informed \\
\hline High (HTE) & Balls attacked without any restriction of region or attacking action \\
\hline N/D (NTE) & Not applicable \\
\hline \multicolumn{2}{|c|}{ Players' Displacement Complexity } \\
\hline \multicolumn{2}{|l|}{ Start } \\
\hline Low (LDS) & Initial positioning has few variations although adjusted to ball position \\
\hline Medium (MDS) & Initial positioning may vary although without exchange of players' positioning on court \\
\hline High (HDS) & Player positioning may vary and players may exchange positions on court \\
\hline N/D (NDS) & Not applicable \\
\hline \multicolumn{2}{|l|}{ Course } \\
\hline Low (LDC) & Single action in a pre-defined displacement path \\
\hline Medium (MDC) & $\begin{array}{l}\text { Execution of two or more actions that demand exchange of directions with a pre-determined } \\
\text { sequence }\end{array}$ \\
\hline High (HDC) & $\begin{array}{l}\text { Execution of two or more actions that demand exchange of directions with a sequence determined } \\
\text { by the game dynamics }\end{array}$ \\
\hline N/D (NDC) & Not applicable \\
\hline \multicolumn{2}{|l|}{ End } \\
\hline Low (LDE) & Recovery without repositioning \\
\hline Medium (MDE) & Repositioning and wait for a new sequence of pre-determined actions \\
\hline High (HDE) & Repositioning and wait for a new sequence of actions determined by the game dynamics \\
\hline N/D (NDE) & Not applicable \\
\hline
\end{tabular}

Table 5. Classes of the pressure parameter: i) rhythm; ii) amplitude of attention; iii) type of start.

\begin{tabular}{ll}
\hline $\begin{array}{l}\text { Rhythm } \\
\text { Low (LR) }\end{array}$ & \multicolumn{1}{c}{ Spatial and temporal constraints } \\
$\begin{array}{l}\text { Medium (MR) } \\
\text { High (HR) }\end{array}$ & $\begin{array}{l}\text { Few actions performed in low velocity } \\
\text { Some sequential actions performed in moderate velocity } \\
\text { N/D (NRT) }\end{array}$ \\
$\begin{array}{l}\text { Amplitude of attention } \\
\text { Low (LA) }\end{array}$ & Not applicable \\
$\begin{array}{l}\text { Medium (MA) } \\
\text { High (HA) }\end{array}$ & $\begin{array}{l}\text { External stimuli that demand strict focus of attention } \\
\text { N/D (NAT) }\end{array}$ \\
$\begin{array}{l}\text { Type of start } \\
\text { Commom (CM) } \\
\text { Free ball (FB) }\end{array}$ & External stimuli that demand focus of attention similar to those of game actions \\
N/D (NST) & Offensive potential of the attack similar to the game \\
\hline
\end{tabular}


Table 6. Classes of the parameter logistic: i) density; ii) simultaneity; iii) cyclicity.

\begin{tabular}{|c|c|c|}
\hline & & Logistic parameters \\
\hline Parameter & \multicolumn{2}{|l|}{ Description } \\
\hline \multicolumn{3}{|l|}{ Density } \\
\hline Low (LD) & \multicolumn{2}{|c|}{ Recovery time superior to activity time } \\
\hline Medium (MD) & \multicolumn{2}{|c|}{ Recovery and activity time are equivalent } \\
\hline High (HD) & \multicolumn{2}{|c|}{ Recovery time inferior to activity time } \\
\hline N/D (ND) & \multicolumn{2}{|c|}{ Not applicable } \\
\hline \multirow[t]{11}{*}{ Concatenation } & \multicolumn{2}{|l|}{ Type } \\
\hline & Out $(\mathrm{OC})$ & Each player executes the task on its turn \\
\hline & Per entry (PE) & $\begin{array}{l}\text { A group of players is completely or partially replaced by another after } \\
\text { performing a task }\end{array}$ \\
\hline & Task relay (TR) & $\begin{array}{l}\text { All players perform a task simultaneously but are separated by groups } \\
\text { that alternate in the performance of different tasks (circuit) }\end{array}$ \\
\hline & Role relay (RR) & $\begin{array}{l}\text { Players of a group assume different roles in a task and alternate roles } \\
\text { until all perform according to every role }\end{array}$ \\
\hline & Simultaneous (SM) & All players perform the same task simultaneously \\
\hline & N/D (NT) & Not applicable \\
\hline & \multicolumn{2}{|l|}{ Substitution criterion } \\
\hline & Task conclusion (TS) & Players are replaced when accomplish a task \\
\hline & Chosen by the coach (SC) & $\begin{array}{l}\text { Players are replaced (or not) according to specific criteria defined by } \\
\text { the coach (e.g. to loose in a dispute or after perform a specific task or } \\
\text { continue to conclude the task successfully, etc) }\end{array}$ \\
\hline & Without substituition (WS) & Have no substituition \\
\hline \multicolumn{3}{|l|}{ Ciclicity } \\
\hline Cyclic (CC) & \multicolumn{2}{|c|}{ An action (or a set of actions) is performed a single time or is repeated after interruption } \\
\hline Acyclical (AC) & \multicolumn{2}{|c|}{ A single action (or a set of actions) is performed several times without an interval } \\
\hline $\mathrm{N} / \mathrm{D}(\mathrm{NC})$ & \multicolumn{2}{|c|}{ Not applicable } \\
\hline
\end{tabular}

$(p>0.05)$. Agreement was above $(0.90)$ in all of the cases, except by the parameters: tactical roles, ball trajectorystart, simultaneity (0.80-0.85) and players' displacement - start (0.70). Satisfactory levels of reliability were achieved in all cases.

\section{RECURRENCE OF ATTRIBUTES AND PARAMETERS IN DRILLS}

Figure 2 displays the results of the model application for analyzing the design tendencies of the sampled drills. Nodes of the graph are aligned by columns. Each column represents a class of parameters. The centrality degree of the node (i.e. the frequency each node is used in the design of the sampled drills) is indicated by its diameter. The node's diameter is proportional to the amount of connected edges. The edges are unidirectional, with left to right orientation. Similarly, to the nodes, the thickness of the edges is proportional to the frequency it connects two nodes.

Fischer's exact test indicated differences in the frequencies of the model's attributes and parameters in the sampled drills $(p<0.001)$, see Figure 3. Most of the drills used the basic sequence (30\%). For the basic complex and $\mathrm{KI}$, most of the drills are, respectively, manifolds and composed by isolated fundamentals. For domains, to the basic complex, the greatest proportion of drills related to technical skills. For KI, most of the drills focused on tactics.

\section{DISCUSSION}

The aim of the present work was to define a model encompassing the attributes and parameters that define the structure of any volleyball training drill. Additionally, we presented an approach for applying the model into the analysis of design tendencies of a set of drills. According to the results, the categorical classes that define the attributes and parameters of the model are pertinent and accurate. Thus, the model systematizes drills' structure by gathering, expanding and organizing designing principles, extending previous works (Shondell and Reynaud, 2002; Andrés and Peña, 2006; Andrés et al., 2007). Besides that, the analytic techniques implemented indicated the model was well-succeeded in capturing the differences of drills design in the assessed sample, summing to other efforts in this regard (Toro and De Baranda Andujar, 2003; Ibáñez et al., 2016).

The model has demonstrated pertinence and accuracy in regards to its attributes and parameters. According to the tests performed, the classes map the contents of the drills precisely. Following the sequence of 


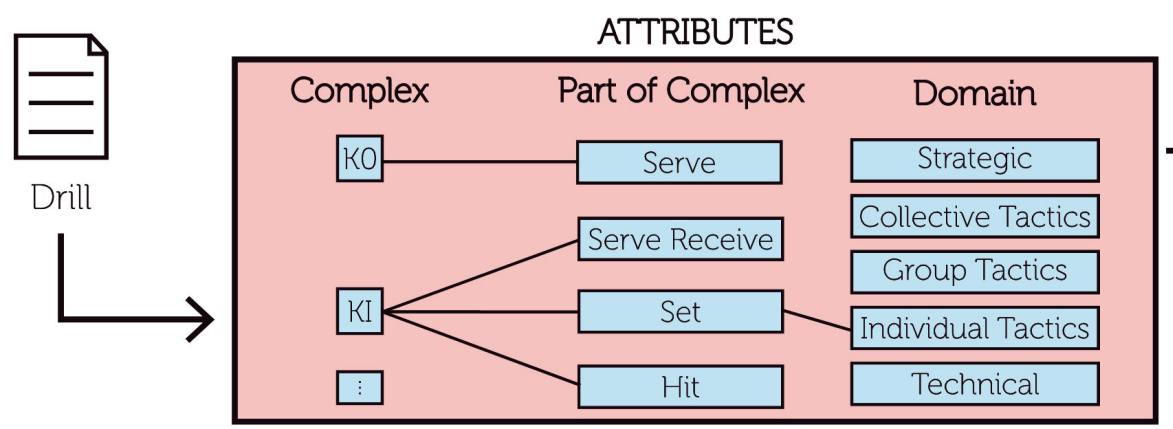

STRUCTURE PARAMETERS
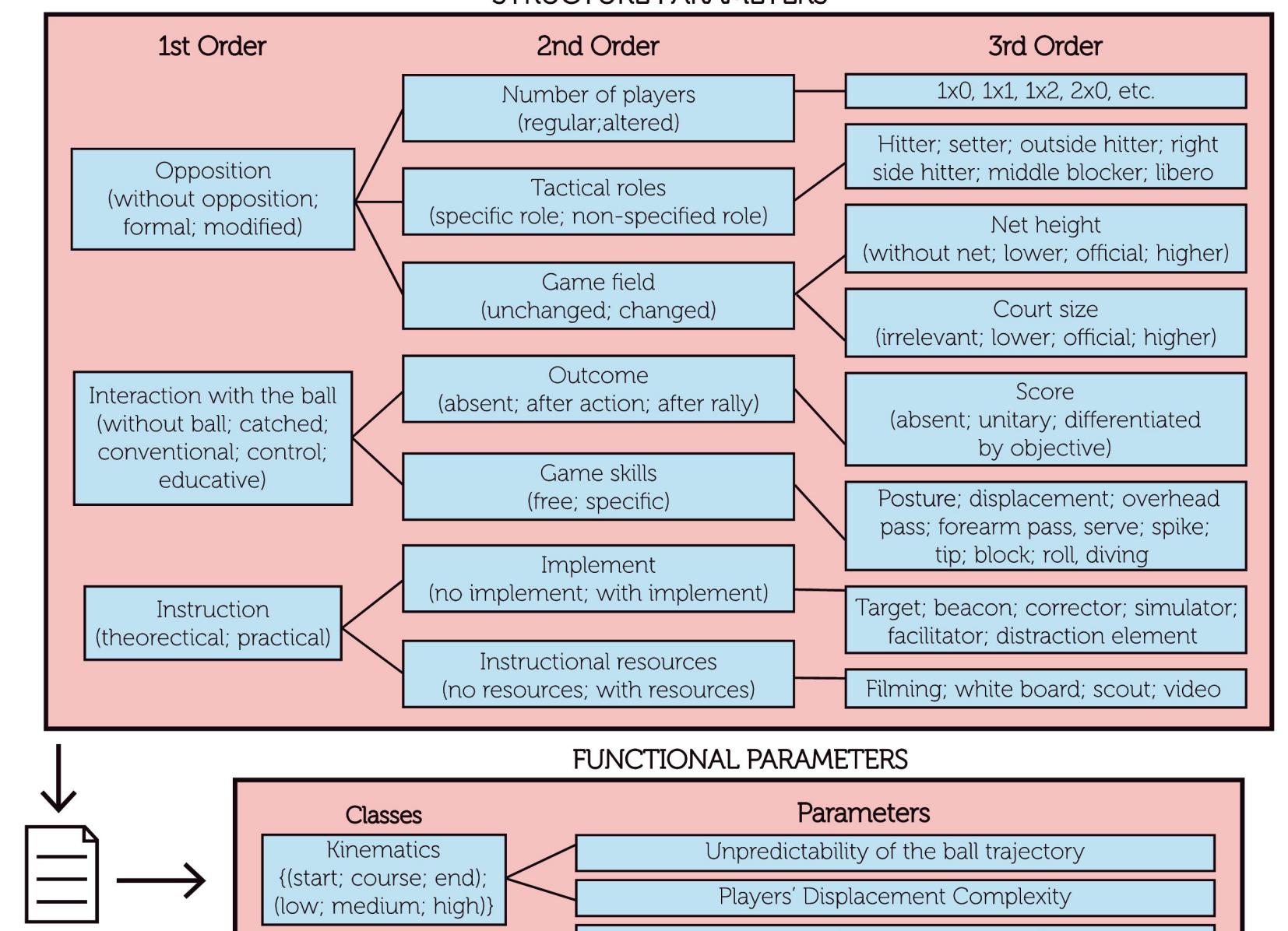

Content structure

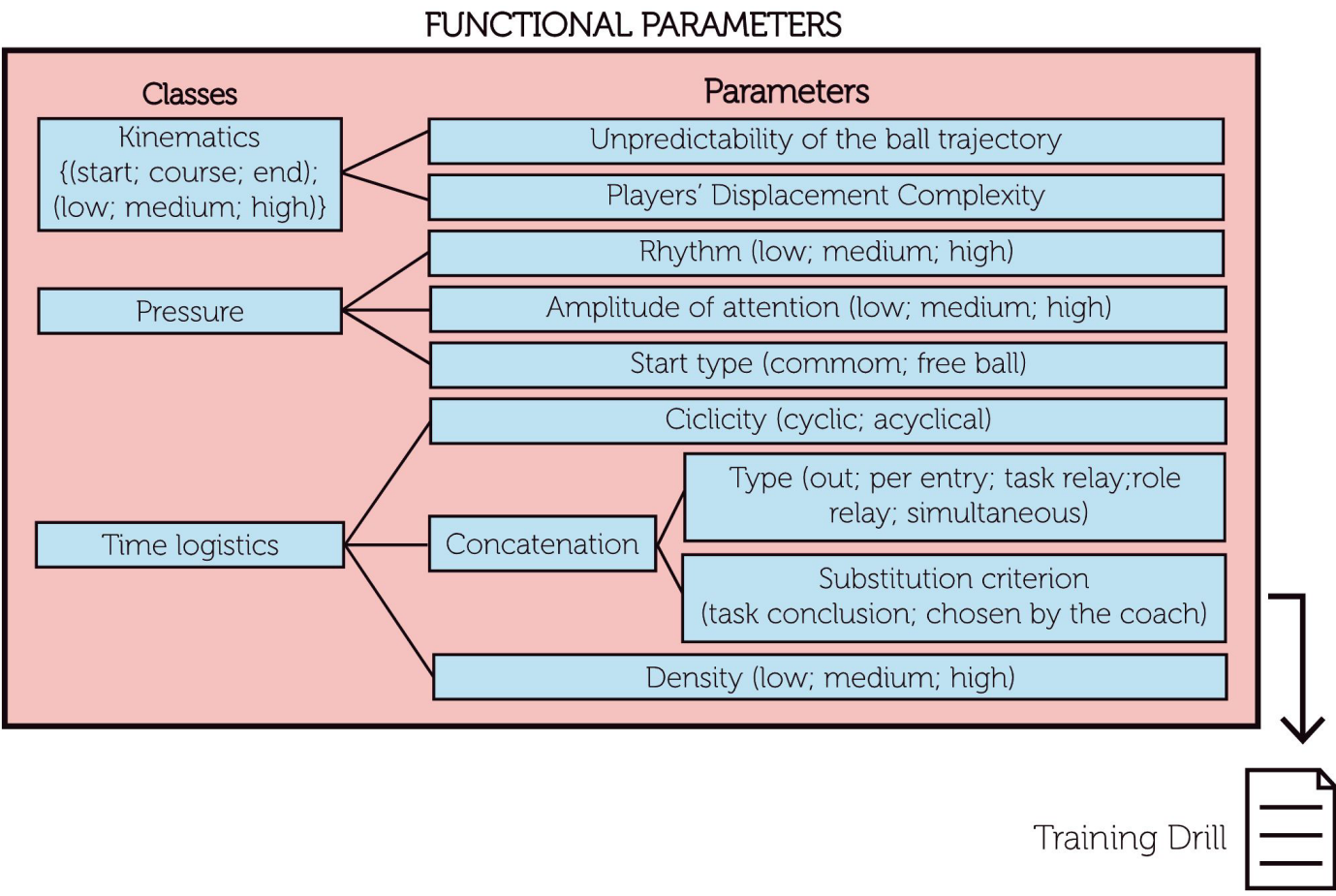

Figure 1. Model of attributes and parameters used in the design of a volleyball's training drill ( $\mathrm{K}=$ game complex; $\mathrm{Kp}=$ complex part; $\mathrm{D}=$ content domain). 


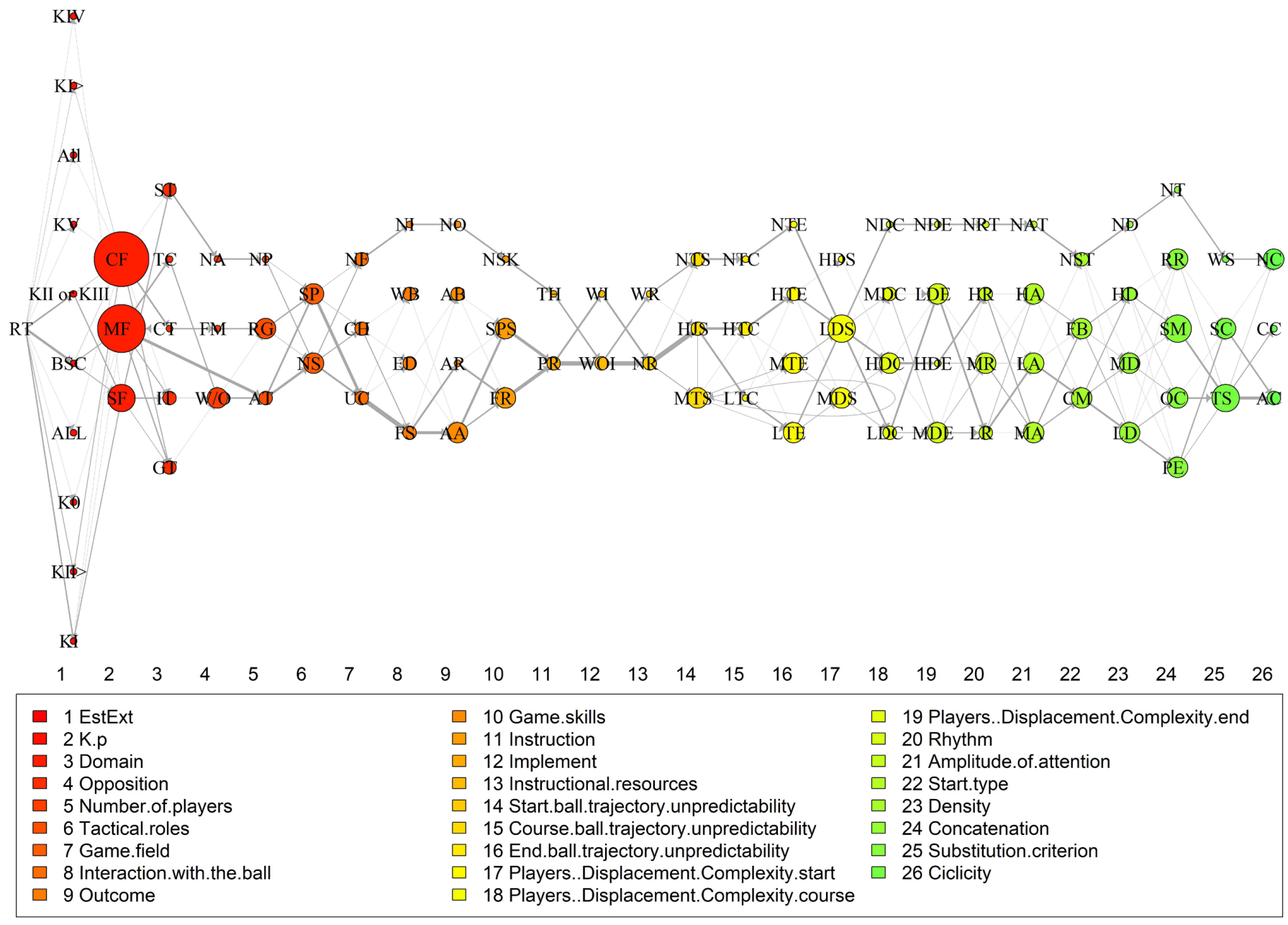

Figure 2. Graph representation of the parameters and attributes utilization in the design of training drills. The labels of the nodes correspond to the abbreviations indicated in Tables 1-6.
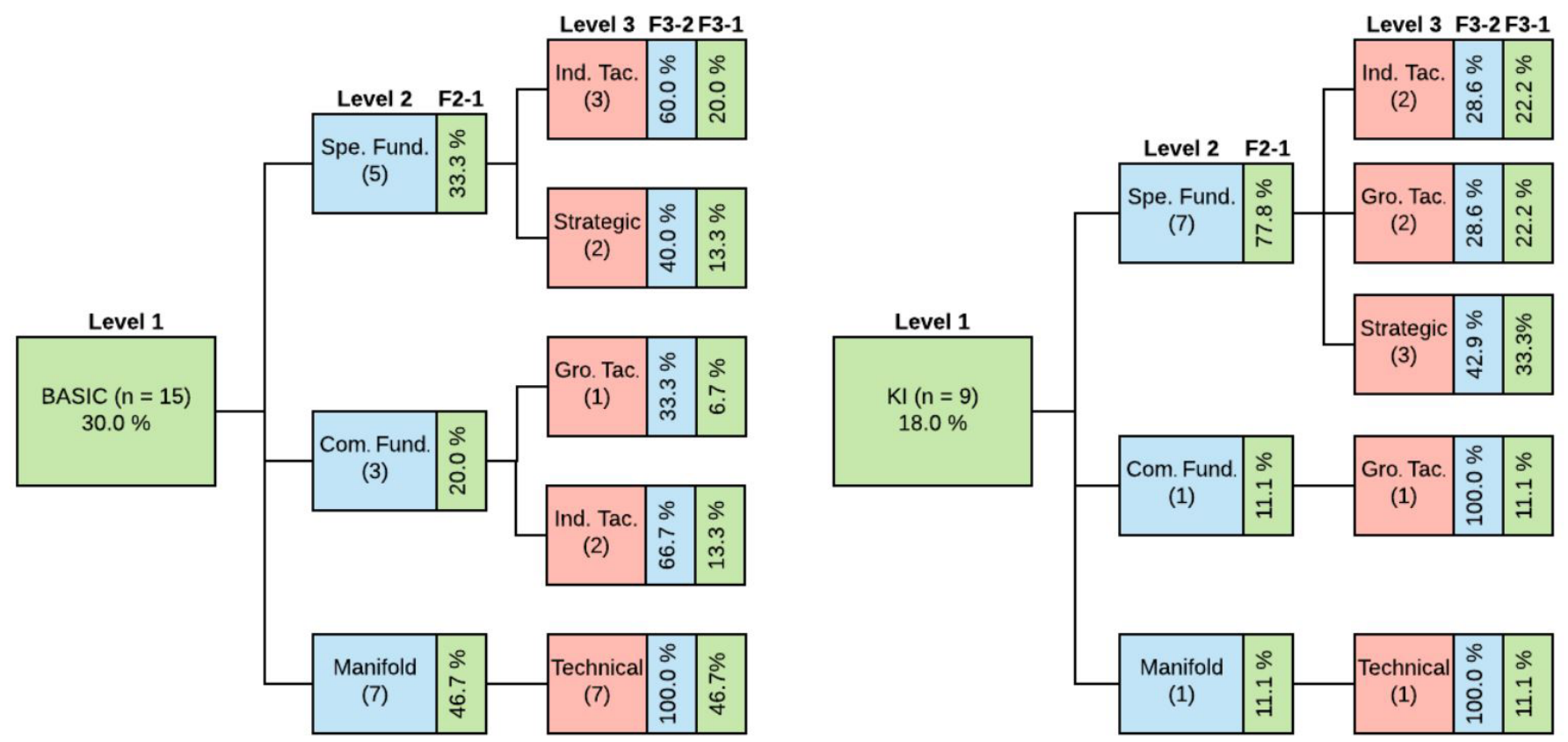

Figure 3. Tree diagram with the proportions of attributes of the complexes Basic and KI (Fj-i: frequency of attribute in $\mathrm{j}$ level according to attribute in i level). 
model levels, it was possible to decompose each drill by relating each element of the drill to a single model class. And, at the end, it was possible to obtain a structural decomposition of the drill sufficient to characterize and compare it to other drills in terms of its structure.

The graph visualization (Figure 2) evidences the diversity of contents and choices in the design of the training drills, assessed through the proposed model. It evidences not only a great number of nodes that are reached by the connections in each level but also a diversity of combinations between nodes. The pertinence and accuracy levels achieved in the attributes and parameters definition supported the assessment of design alternatives. It is worth noting that in the first levels of the model (left-right orientation of the graph display) nodes present higher centrality, indicating a greater recurrence (greater diameter of nodes). It may be due to the fact that in the first levels there are fewer design options in comparison to the higher resolution of subsequent parameters, which provide drills specifications, for instance, in the functional level.

The diversity of design alternatives is reinforced by the analysis of specific sub-sets of the sample, such as those presented in the tree diagrams (Figure 3). In the case a set of drills constitute the training repository of a coach, through this analytic approach it is possible to check the consistency between the coach's drills and the intentions previously pointed out in the season planning, as suggested elsewhere (Cushion et al., 2012; Ibáñez et al., 2016). For instance, high-level championship winning teams may have approximately $70 \%$ efficiency in the KI complex (Palao and López-Martínez, 2012) against $40 \%$ in KII. Comparatively, The present proportion of $18 \%$ would indicate a low proportion.

These evidences suggest how the model can be applied to analyze the drills and the design tendencies of coaches both for a single drill and in terms of sequences of drills in one or multiple training sessions. It fosters elements to the coach self-reflection on his practices' decisions (Cushion et al., 2012) and is aligned with studies that investigate the manipulation of training constraints to improve tactical learning, game intelligence and creative motor actions (Davids et al., 2012; Light et al., 2014; Orth et al., 2017).

Results obtained with Fischer's exact test indicated the design alternatives used in the sample with reference to the game complexes were significantly different from each other. These differences corroborate the fact the model structure covers several arrangements between attributes, which can naturally be extended to the parameters.

The study presents the limitation related to a broader empirical testing of the adequacy between its attributes and parameters and the phenomenon itself - i.e. the volleyball training drills. Larger and more diversified samples of drills from different training levels and coaches should be assessed in order to provide additional evidences of the model's quality.
In synthesis, the present contribution enables a systematic and explicit presentation of the features of each training drill. It also supports a more systematic intervention of the coaches, by disrupting the notion of drills' design as a necessarily empirical task. The support provided by the model for the elaboration of drills may be of special value for less experienced coaches. Thus, it may contribute to the curriculum of volleyball coaches' courses.

\section{FUNDING}

The present work did not have financial support of any kind for its realization.

\section{CONFLICTS OF INTEREST}

The authors declare no conflicts of interest.

\section{ACKNOWLEDGEMENTS}

We thank Milena Cristina Machado da Costa for the technical support in the design of the images available in the text.

\section{REFERENCES}

Andrés JMP, Peña SG. Efecto de la forma de organización de los ejercicios sobre el número de repeticiones y la percepción del proceso en la iniciación al voleibol. EF Dep. 2006;101(5).

Andrés JMP, Toro EO, Mula CP. Efecto de la forma de organización de un trabajo de salida de recepción en voleibol sobre la participación, la calidad de ejecución y la frecuencia cardíaca. RED. 2007;21(1):5-11.

Côté J. The development of coaching knowledge. Int J Sports Sci Coaching. 2006;1(3):217-22. http://dx.doi. org/10.1260/174795406778604609.

Cushion C, Nelson L, Armour K, Lyle J, Jones R, Sandford R, et al. Coach learning and development: a review of literature. Leeds: Sport Coach UK; 2010 Jan.

Cushion C, Ford PR, Williams AM. Coach behaviours and practice structures in youth soccer: implications for talent development. J Sports Sci. 2012;30(15):1631-41. http://dx.doi.org/10.1080/02640414.2012.721930. PMid:23016800.

Davids K, Araújo D, Hristovski R, Passos P, Chow JY. Ecological dynamics and motor learning design in sport. In: Hodges $\mathrm{N}$, Williams MA, editors. Skill acquisition in sport: research, theory \& practice. London: Routledge; 2012.

Ferrauti A, Pluim BM, Weber K. The effect of recovery duration on running speed and stroke quality during intermittent training drills in elite tennis players. J Sports Sci. 2001;19(4):235-42. http://dx.doi. org/10.1080/026404101750158277. PMid:11311021.

Ghosh AK. Heart rate and blood lactate responses during execution of some specific strokes in badminton drills. Int J Appl Sports Sci. 2008;20(2):27-36.

Hileno R, Buscà B. Observational tool for analyzing attack coverage in volleyball. Rev Int Med Cien Activ Fis Dep. 2012;12(47):557-70. 
Ibáñez SJ, Feu S, Cañadas M. Sistema integral para el análisis de las tareas de entrenamiento, SIATE, en deportes de invasión. EBM RECIDE. 2016;12(1):3-30.

Lamas L, Barrera J, Santana FL, Ugrinowitsch C. Team sports modeling: building a framework for quantitative approaches. In: Nascimento JV, Ramos V, Tavares F, editors. Jogos desportivos: formação e investigação. 20. ed. Florianópolis: UDESC; 2013. P .439-62.

Landis JR, Koch GG. The measurement of observer agreement for categorical data. Biometrics. 1977;33(1):159-74.

Leite N, Vaz L, Vitor M, Sampaio J. Coaches perceived importance of drills items in basketball players'long-term development. Rev Psi Dep. 2009;18(3):457-61.

Light L, Harvey S, Mouchet A. Improving 'at-action'decisionmaking in team sports through a holistic coaching approach. Sport Educ Soc. 2014;19(3):258-75. http:// dx.doi.org/10.1080/13573322.2012.665803.

Matias CJAS, Greco PJ. Conhecimento tático-estratégico dos levantadores brasileiros campeões de voleibol: da formação ao alto nível. Rev Bras Educ Fis. Esp. 2011;25(3):513-35.

Milistetd M, Mesquita I, Nascimento JV, Sousa AEP So. Concepções de treinadores "experts" Brasileiros sobre o processo de formação desportiva do jogador de voleibol. Rev Bras Educ Fis Esp. 2010;24(1):79-93.

Moraes JC. Determinantes da dinâmica funcional do jogo de voleibol: estudo aplicado em seleções adultas masculinas [dissertação]. Porto: Universidade do Porto; 2009.

Morcillo JA, Moreno OPC, González RAM, Sánchez FJN. Aproximación a la utilización de medios específicos de entrenamiento en la enseñanza del fútbol. Lecturas: EF Dep. 2001;39(7):1-1.

Nevill A, Atkinson G, Hughes M. Twenty-five years of sport performance research in the Journal of Sports Sciences. J Sports Sci. 2008;26(4):413-26. http://dx.doi. org/10.1080/02640410701714589. PMid:18228169.

Nieman DC, Kernodle MW, Henson DA, Sonnenfeld G, Morton DS. The acute response of the immune system to tennis drills in adolescent athletes. Res Q Exerc Sport. 2000;71(4):403-8. http://dx.doi.org/10.1080/02701367. 2000.10608923. PMid:11125538.

Orth D, van der Kamp J, Memmert D, Savelsbergh GJP. Creative motor actions as emerging from movement variability. Front Psychol. 2017;8:1903. http://dx.doi.org/10.3389/ fpsyg.2017.01903. PMid:29163284.
Palao JM, Manzanares P, Ortega E. Design and validation of an observation instrument for technical and tactical actions in indoor volleyball. Eur J Hum Mov. 2015;34:75-95.

Palao JM, López-Martínez AB. Establecimiento de objetivos a partir del análisis del juego para el trabajo técnico-táctico en voley-playa: un caso práctico. Rev Espan Edu Fis Dep. 2012;35(396):1-47.

Partington $M$, Cushion C. An investigation of the practice activities and coaching behaviors of professional toplevel youth soccer coaches. Scand J Med Sci Sports. 2013;23(3):374-82. http://dx.doi.org/10.1111/j.16000838.2011.01383.x. PMid:22092356.

Reid M, Duffield R, Dawson B, Baker J, Crespo M. Quantification of the physiological and performance characteristics of on-court tennis drills. Br J Sports Med. 2007;42(2):14651. http://dx.doi.org/10.1136/bjsm.2007.036426. PMid:17681984.

Resende R, Sarmento H, Falcão W, Mesquita I, Romero J. Coach education in volleyball: a study in five countries. J Phys Edu Sport. 2014;14(4):475-84.

Sá PJRA. Exercícios complexos de treino: influência das variáveis espaço, tempo e número de jogadores na intensidade do esforço de um exercício de treino [dissertação]. Porto: Universidade do Porto; 2001.

Santana F, Fellingham G, Rangel W, Ugrinowitsch C, Lamas L. Assessing basketball offensive structure: the role of concatenations in space creation dynamics. Int J Sports Sci Coach. 2019;14(2):179-89.

Sarmento H, Bradley P, Travassos B. The transition from match analysis to intervention: Optimising the coaching process in elite futsal. Int J Perform Anal Sport. 2015;15(2):47188. http://dx.doi.org/10.1080/24748668.2015.11868807.

Shondell D, Reynaud C. The volleyball coaching bible. Champaign: Human Kinetics; 2002.

Spooner $\mathrm{E}$. The science of volleyball practice development and drill design: from principles to application. Bloomington: iUniverse; 2012.

Toro EO, De Baranda Andujar PS. El diseño de tareas en el fútbol base: su aplicabilidad al puesto específico del portero. Cuad. Psi. Dep. 2003;3(1):15-32.

Vélez DC, Piñar M, López FA. Factores que influyen en la organización de las tareas para la mejora de los tiempos de práctica en baloncesto. EF Dep. 2004;10(74):1. 